\title{
Cost and comfort optimisation for buildings and urban layouts by combining dynamic energy simulations and generic optimisation tools
}

\author{
T. Nguyen Van, A. Miyamoto, D. Trigaux \& F. De Troyer \\ Katholieke Universiteit Leuven, Belgium
}

\begin{abstract}
In recent decades, as a result of continuously increasing urbanization and climate change, energy saving has become a critical issue. Due to the high dwelling density, most compact urban areas have limited possibilities for natural ventilation combined with reduced solar radiation. As a consequence, a balance has to be found between reduced comfort and increased energy cost for cooling or heating. The aim of this study is to minimise the energy consumption and optimize thermal comfort of terraced houses in different urban patterns, by using natural ventilation and considering solar radiation. This study analyses different parameters on the level of buildings and urban layouts. The building characteristics include building sizes, window design, materials and internal wind permeability. The urban layouts consist of different building heights, setbacks and road widths. Energy consumption and thermal comfort are calculated by a dynamic simulation using EnergyPlus. Then the generic optimisation tool GenOpt is used to search for the lowest cost to reach a predefined minimum thermal comfort. Both the temperate climate in Belgium and the tropical climate in Vietnam were analysed to check the efficiency and robustness of the models. Conclusions are drawn for sketch design in the given contexts.

Keywords: building layout, energy consumption, natural ventilation, thermal comfort, urban layout.
\end{abstract}

\section{Introduction}

A majority of the world population lives in temperate and tropical climatic zones. These contexts are characterised by distinct latitude, climate, terrain and so on. In 
these climatic zones a large amount of energy is often required for heating and/or cooling in order to reach thermal comfort. Thus Belgium as temperate climate and Vietnam as tropical climate are chosen as case study in this research. To date, buildings account globally for about $40 \%$ of the total energy consumption and contribute to a significant amount of carbon dioxide emissions [1]. Moreover, heat island effect, caused by urbanization, result in an increase of the cooling energy demand in high-density building areas [2]. Hence, thermal comfort and energy saving issues are a challenge for building designers.

In this context, decisions taken in the early design stages have a major influence on energy consumption in dwellings. First, the urban layout has an impact on the total energy use of more than $30 \%$ in offices and more than $19 \%$ in housing [3]. Second, building geometry and material choice impact strongly on comfort and energy saving. Next to those design parameters, the occupant behaviour, in terms of using electric equipment, HVAC system lighting and adapted clothing, is also a crucial factor to reduce energy demand. The impact of occupant behaviour on house energy demand for space heating has been investigated in various studies [4-6]. These studies consider different factors related to occupation modes and occupant behaviour that impact on building energy use. As an example, a survey has shown that an adapted occupant behaviour result in energy saving up to $40 \%$ for HVAC and lighting [7].

However only a few studies optimize both building geometry and urban layout, using a parametric simulation and considering effects of natural ventilation and solar radiation on energy cost, thermal comfort and human responses. The aims of this research project are to evaluate the model and to predict building energy consumption in two different climate contexts. Via a parametric simulation building types are optimized, looking at the urban layout, building orientation, window design, overhangs and materials. EnergyPlus is used for the dynamic energy calculations and GenOpt is used to search for an optimum out of the multiple design options.

\section{Methodology}

In this study a six step procedure is used for the simulations. (1) The urban layouts and terraced houses are simplified and crucial parameters are selected. (2) The wind pressure coefficient $(\mathrm{Cp})$ on the facades and the roof are calculated for 36 orientations. (3) The Fanger model for comfort evaluation is implemented. (4) A stepwise strategy to strive for occupant's comfort is defined for the winter and summer conditions. For the winter conditions this strategy consists of adapt clothing and, if the comfort condition cannot be reached, start heating. For the summer conditions, adapting process consists of consecutive steps: adapt clothing, manage natural ventilation, switch on fans for air circulation and start the cooling or heating system. (5) We analyze a typical terraced house unit with 6 different urban layouts for 12 orientations. (6) An optimization method and an objective function are used to search for the lowest energy cost to reach a predefined comfort. All design parameters of both building and urban scale levels are varied and sent to EneryPlus [8] by the optimization tool GenOpt [9]. 


\subsection{Simplifying urban scale}

As illustrated in fig. 1, a simplified urban layout model, consisting of rectangular buildings and orthogonal streets, is defined for the simulations. This urban layout is described with following key parameters: the height of the surrounding buildings, road width, building setback and terraced house width and depth as shown in fig.1. For this simplified urban fragment, the percentages of circulation, residential-open and residential-built-up are calculated, using the element method for cost control $[10,11]$.

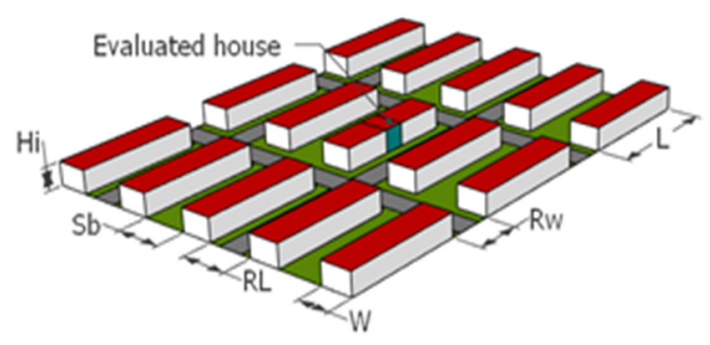

Figure 1: Simplified urban layout model.

\subsection{Simplifying building scale}

The simulations are carried out for one housing unit, located in the centre of the urban layout fig. 1. The terraced house type was selected as representative for urban and suburban areas in Belgium and Vietnam. The simple model for this dwelling type is shown in fig. 2 and includes seven thermal zones: a living room, a kitchen, 4 bedrooms and a central stair case. The geometry of the reference house is $6 \mathrm{~m}$ width, $16 \mathrm{~m}$ depth, $3 \mathrm{~m}$ floor height, 4 by $1.5 \mathrm{~m}$ window, $1 \mathrm{~m}$ overhang depth and typical materials based on [12].

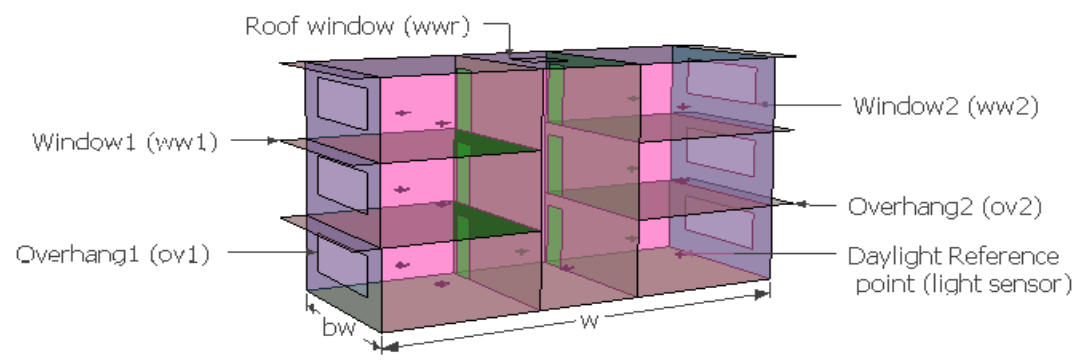

Figure 2: $\quad$ Terraced house unit with overhang depth varying from $0.1 \mathrm{~m}$ to $2 \mathrm{~m}$ and window widths varying from 1 to $4 \mathrm{~m}$.

Opening schedule of the internal door and windows is controlled by the Energy Management System (EMS) of EnergyPlus. Control rules for the EMS were developed based on time schedules, natural ventilation and PMV values for each time step. As shown in Table 1 and Table 2, the design parameters for the terraced 
house unit are varied within specific ranges and discrete variables of materials. Simulations are carried out using both low and high insulated building elements for floors on grade, external walls, roofs and glazing.

Table 1: Numerical variables and their design options.

\begin{tabular}{|l|c|c|c|c|}
\hline Design parameter & Abbreviation & $\begin{array}{c}\text { Initial } \\
\text { value }\end{array}$ & Range (m) & $\begin{array}{c}\text { Step size } \\
\text { (m) }\end{array}$ \\
\hline Urban layout: \\
\hline Surrounding building heights & $\mathrm{H}_{1}$ to $\mathrm{H}_{14}$ & 9 & 1 to 27 & 3 \\
\hline Road widths & $\mathrm{Rw}, \mathrm{R} 1$ & 12 & 12 to 24 & 4 \\
\hline Building setback & $\mathrm{Sb}$ & 12 & 12 to 24 & 4 \\
\hline Terraced row length & $\mathrm{L}$ & 40 & 40 to 120 & 10 \\
\hline Terraced house geometry: & ov1 & 4 & 0.1 to 2 & 0.2 \\
\hline Front façade overhang & ov2 & 4 & 0.1 to 2 & 0.2 \\
\hline Rear façade overhang & ww1 & 4 & 1 to 4 & 0.5 \\
\hline Front window & ww2 & 4 & 1 to 4 & 0.5 \\
\hline Back window & wwr & 4 & 1 to 4 & 0.5 \\
\hline Roof window &
\end{tabular}

Table 2: $\quad$ Material design options with discrete variables.

\begin{tabular}{|l|l|}
\hline Material layers of construction elements & Abbreviation \\
\hline Mortar, hole clay brick, mortar. & ExWall1 \\
\hline Mortar, hole clay brick, hole clay brick, mortar. & ExWall2 \\
\hline Mortar, hole clay brick, air gap, hole clay brick, mortar. & ExWall3 \\
\hline Mortar, hole clay brick, Insulation, Hole clay brick, Mortar. & ExWall4 \\
\hline $\begin{array}{l}\text { Outer brick skin, air cavity_3cm, rock wool EW, concrete hollow } \\
\text { blocks, gypsum plaster. }\end{array}$ & ExWall5 \\
\hline $\begin{array}{l}\text { Outer brick skin, air cavity 3cm, rock wool EW, concrete massive } \\
\text { blocks, gypsum plaster. }\end{array}$ & ExWall6 \\
\hline Mortar, brick clay, thermal mass2, mortar & InWall1 \\
\hline Mortar, brick clay, thermal mass3, mortar & InWall2 \\
\hline Mortar, brick clay, thermal mass4, mortar & InWall3 \\
\hline Roof asphalt, concrete roof slab, ceiling mortar & Roof1 \\
\hline Roof asphalt, roof insolation, concrete roof slab, mortar & Roof2 \\
\hline $\begin{array}{l}\text { EPDM, PUR_FR, aluminium, sloping layer, concrete slab, gypsum } \\
\text { plaster }\end{array}$ & Roof3 \\
\hline $\begin{array}{l}\text { Clay roof tiles, PUR_PR, wood fibre board, aluminium, air cavity } \\
\text { 2cm, gypsum board }\end{array}$ & Roof4 \\
\hline Single glazed timber frame & Glazing1 \\
\hline Clear glass 6mm & Glazing2 \\
\hline PYR B clear glass 6mm & Glazing3 \\
\hline Clear glass 6mm, air 6mm, clear glass 6mm & Glazing4 \\
\hline Clear glass 4mm, air 15mm, clear glass 4mm & Glazing5 \\
\hline REF A clear mid 6mm, argon 13mm, clear glass 6mm & Glazing6 \\
\hline Clear glass 4mm, argon 15mm, LoE clear glass 4mm & Glazing7 \\
\hline $\begin{array}{l}\text { LoE clear glass, argon 15mm, clear glass, argon 15mm, LoE clear } \\
\text { glass 4mm }\end{array}$ & Glazing8 \\
\hline
\end{tabular}




\subsection{Wind pressure coefficient $(\mathrm{Cp})$}

The TNO Cp-generator, developed in the Netherlands, is used to calculate the wind pressure coefficient $(\mathrm{Cp})$ values on facades and roofs of block-shaped buildings. This generator is based on finite element calculations and has been verified with wind tunnel experiments [13] and by measured data [14]. This validation showed a rather good agreement between measured and calculated results. The $\mathrm{Cp}$-Generator should only be used for situations without complex building configurations. A similar approach, using this tool, was applied in other studies to obtain the $\mathrm{Cp}$ value for a large urban fragment [15].

\subsection{Multiple linear regressions for wind pressure coefficient (Cp) values}

For a specific wind orientation the $\mathrm{Cp}$ value in the middle of the windward façade of the terraced row, situated in the middle of the urban fragment, depends on 19 independent parameters. An overview is provided in table 1: terraced row length (L), terraced row depth (w), width of road parallel with terraced row (Rw), width of road perpendicular to terraced row $(\mathrm{Rl})$, building setback $(\mathrm{sb})$ and the height of the fourteen surrounding buildings $\left(\mathrm{H}_{\mathrm{i}}\right)$ (with $\mathrm{i}=1$ to14 thus $\left.5+14=19\right)$. The same dependency is true for the leeward façade and the roof. The theoretical combinations that can be derived by varying each parameter are very large. Therefore in a first step the "Latin Hypercube Sampling method" is applied to generate 200 combinations of 19 independent parameters. In a second step the Cp values of those combinations are calculated based on the TNO Cp-generator. In a third step, via multiple linear regression analysis, the coefficients of the equation, predicting the $\mathrm{Cp}$ values based on the neighbourhood parameters, are derived. For example, one regression function for the front façade is:

$$
\mathrm{C} \mathrm{p}_{\mathrm{front} 1}=\mathrm{a}_{\mathrm{f} 1} * \mathrm{Hi}+\mathrm{a}_{\mathrm{f} 2} * \mathrm{~L}+\mathrm{a}_{\mathrm{f} 3} * \mathrm{w}+\mathrm{a}_{\mathrm{f} 4} * \mathrm{Rw}+\mathrm{a}_{\mathrm{f} 5} * \mathrm{R} 1+\mathrm{a}_{\mathrm{f} 6} * \mathrm{Sb}+\text { intercept. }
$$

The model that has to be considered in order to obtain stable results consists of five building rows in depth direction, three buildings rows in width direction and a air volume height that is equal to 5 times the building height. In this study all 14 buildings surrounding the considered building were assumed the same height, but this height can be different in each model. In a next step, the same approach can be followed for another wind direction. In order to keep the model manageable only 36 orientations are considered, thus varying in steps of $10^{\circ}$. Fig. 3 compares the $\mathrm{Cp}$ values obtained from the TNO $\mathrm{Cp}$-generator with those predicted by the linear regression function. The results of one geometric variant are shown for the front and back façade, and the roof, for the 36 wind directions. For all other variants a similar good fit could be found. As the "test reference year" (TRY) in EnergyPlus contains for each hour the wind speed and wind direction, linear approximations are used to derive the driving forces for natural ventilation. Based on opening characteristics and dwelling wind-permeability the inside air velocity is calculated. This air speed is then used for predicting thermal comfort based on the Fanger model. 


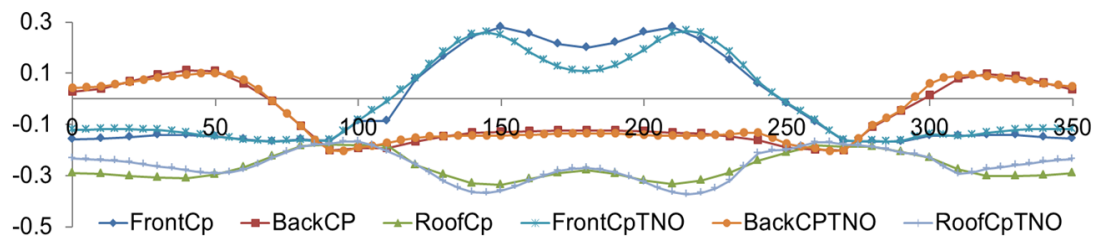

Figure 3: FrontCp, BackCp and RoofCP are wind pressure coefficient values from multiple linear regression functions.

\subsection{Comfort evaluation and strategy based on dynamic schedules for ventilation, fan, cooling and heating}

Fanger [16] developed a thermal load index consisting of a "predicted mean vote" (PMV) on a 7 points scale from "hot" $(+3)$ over "neutral" up to "cold" $(-3)$, based on the heat balance between the body and the environment. His work was the basis for different thermal comfort standards such as the ASHRAE Standard 55-92 and ISO 7730 [17] and [18]. The thermal comfort range is defined for PMV values between -0.5 and +0.5 . The PMV can be used to simulate control actions from "passive" to full HVAC [19].

In this study this approach was implemented in the following procedure: (1) the PMV values with zero air velocity and minimum cloth value is calculated via the "Energy management System" (EMS) in EnergyPlus. (2) In tropical climate, if the PMV value is higher than +0.5 , cooling via natural ventilation is tested up to its limits, if the PMV is still above +0.5 fans are switched on. In the living areas, fans with three speed levels generate a wind speed of respectively $0.2,0.4$ and $0.6 \mathrm{~m} / \mathrm{s}$. In the bedrooms, fans with two speed levels $(0.2$ and $0.4 \mathrm{~m} / \mathrm{s})$ are provided. When the maximal fan velocity is set and comfort is not yet reached, windows are closed and the cooling system is switched on with a set point of $27^{\circ} \mathrm{C}$. (3) In temperate climate, if the PMV value is lower than -0.5, occupants increase cloth value. (4) When the maximum cloth value is set and comfort is not yet reached, the heating system is switched on with a set point of $20.5^{\circ} \mathrm{C}$.

In temperate climate as Belgium, the highest cloth value is 1.5 in living rooms and 3.0 in bed rooms. In that case, occupants adapt their behaviour by increasing the number of blankets during the night [20].

For the simulations activity levels of 1.2 met for the living room and 0.7 met for the bedrooms are considered. However, the activity level 1.0 for bed room is applied due to effect of a transition period from the activity in the living room to the rest in the bed rooms in a tropical climate.

In urban areas adults with a modern life style have a full time job and children go to school. Therefore the living room, kitchen and staircase are assumed to be used from6:00 to 9:00 and from 17:00 to 22:00 during working days. In the weekend, the living room is used from6:00 to 22:00. The bedrooms are used from 0:00 to 5:00 and from 22:00 to 24:00.

In the Vietnamese dwelling type, shading devices consist of balconies and flexible overhangs, which depth is varying depending on the orientation of building and day time. In the Belgian variant, no balconies, overhangs or shadings 
are defined but the windows and main doors are installed 0.1 to $0.2 \mathrm{~m}$ deeper in the façade surface resulting in short overhangs.

All lights in the analysed dwelling are controlled by occupation schedules and luminance levels using two sensors in each zone. The luminance levels for the living room and kitchen, circulation, and bedroom area are respectively $300 \mathrm{~lx}$, $200 \mathrm{~lx}$ and $150 \mathrm{~lx} .69 \mathrm{~lm} / \mathrm{W}$ LED lights are installed in all zones.

\section{Case study}

The aim of case study is evaluating the model and then elaborating a complicated optimization model. As shown in fig. 4, we selected six extreme urban layouts to analyse the energy consumption of the terraced unit in temperate and tropical climate. In Case 1 to 3 narrow streets are considered (build up ratio of 52\%), limiting the possibilities for natural ventilation and direct solar radiation. In Case 4 to 6 wide streets are analysed (build up ratio of 25\%), making natural ventilation and direct solar gains possible.

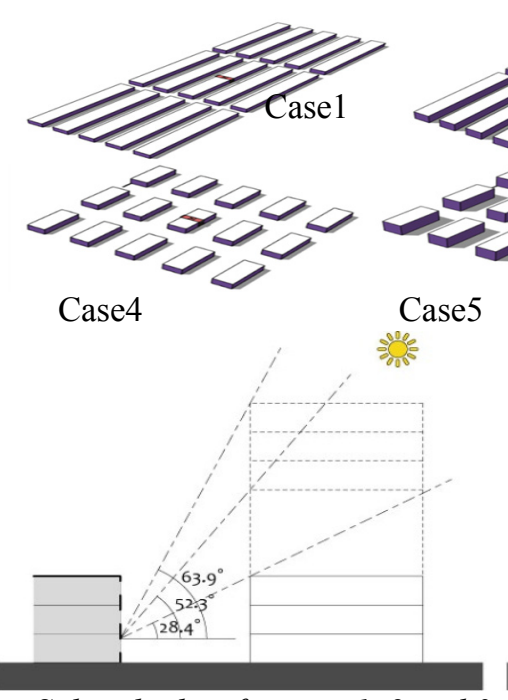

Solar shadow for case 1, 2 and 3

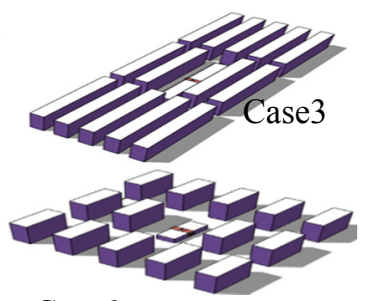

Case6

Figure 4: Six urban layouts with different building density.

\section{Results}

\subsection{Case study results in Vietnam situation}

In this model natural ventilation occurs during the night when the indoor air temperature is higher than the outside temperature. During the day there is not ventilation in the living room and kitchen because the outside temperature is normally higher than the indoor air temperature. The results show that the building 
orientation (e.g.: $90^{\circ}=$ façade facing East) has a major impact on low-density urban layouts. The orientation has a lower impact in the high-density cases (case 2, 3 and 6) as shown in fig. 5, fig. 6 and fig. 7. Moreover the results show that increasing obstruction heights can reduce the energy use for cooling and fans because the solar radiation is blocked.

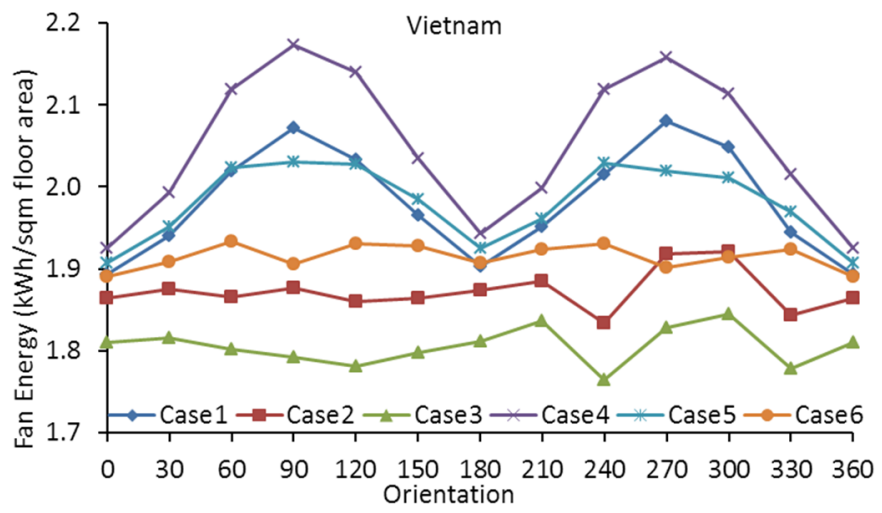

Figure 5: Fan energy of different orientations of six cases.

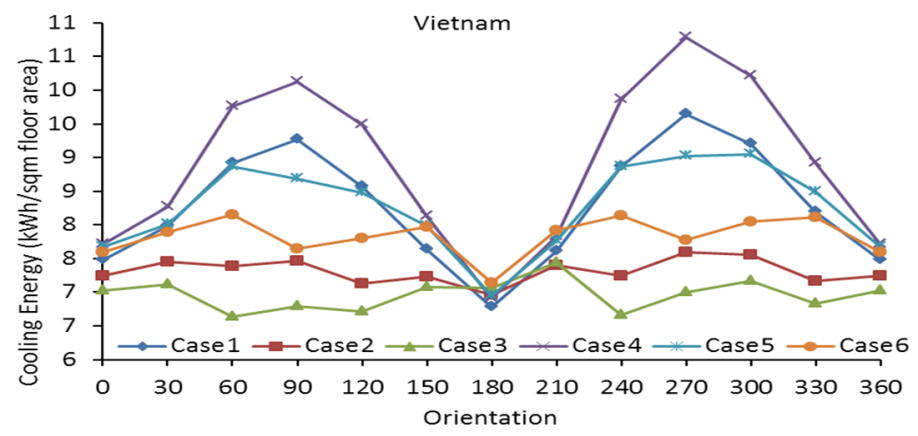

Figure 6: Cooling energy of different orientations of six cases.

Optimization simulation with 15 parameters of both urban and building scale is done by coupling optimization algorithms of GenOpt with EnergyPlus. This design space is $8.7 * 10^{11}$ design options and an EnergyPlus simulation for this complicated model takes about 4 to 5 minutes. Hence, a huge time will be used to calculate all options of the design space. Consequently, our model needs 18 hours to complete the simulations with Del Precision T7500 computer and window 7.

Minimal energy base on optimisation is reached for following, building parameters fig. 8: windows with $25 \%$ both façades, two glass layers windows, $1.1 \mathrm{~m}$ overhang, $20 \mathrm{~cm}$ clay brick external walls, and minimum roof window. Urban parameters are $35.45 \%$ building density and South orientation. All parameters can be adapted for different orientations to reduce solar gains via 


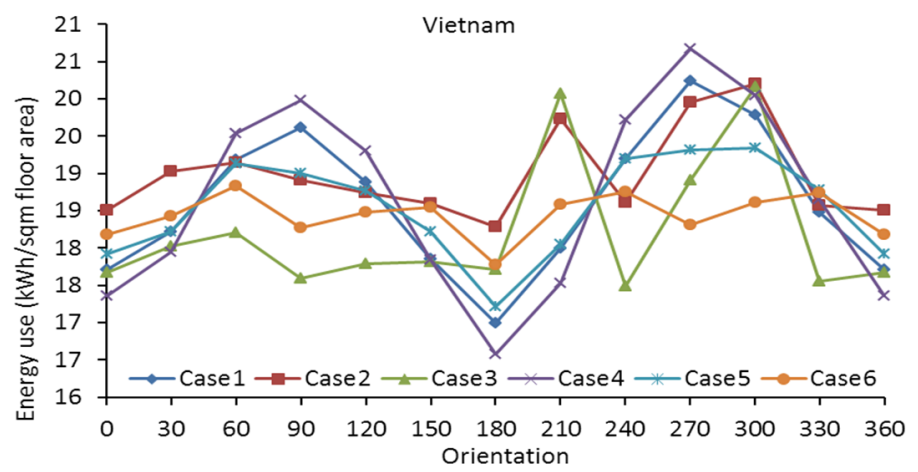

Figure 7: Energy use (cooling with "ideal load", fan energy and lighting) of six cases versus orientations.

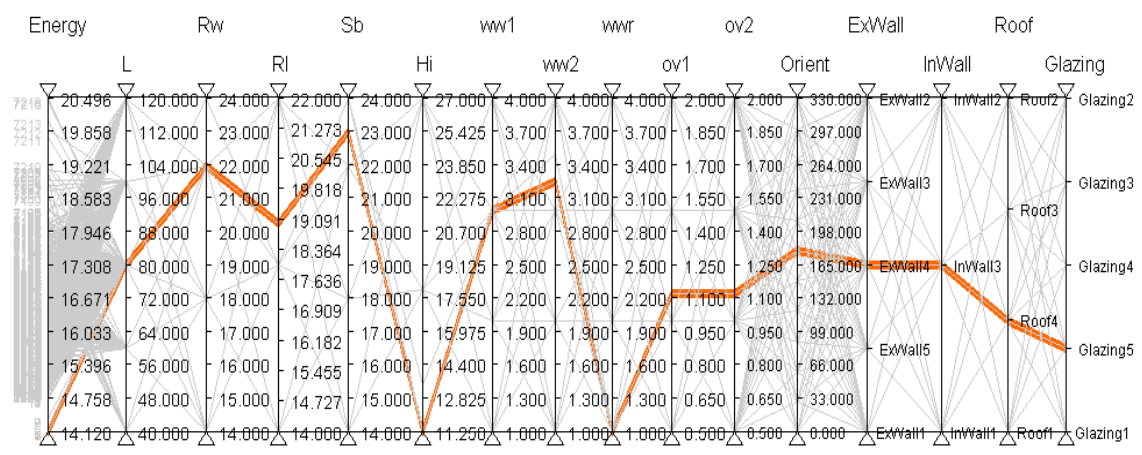

Figure 8: Parameters for optimal energy use are on yellow line based on design alternatives which were searched by optimization algorithms of GenOpt in tropical climate - Vietnam.

radiation and maximum natural ventilation when inside temperature is higher than outside. Therefore, if some parameters are fixed, this model is able to deliver another optimal parameter set.

\subsection{Case study results in Belgium situation}

The model was also tested with temperate climate of Belgium. The results show that the building orientation has high impact in the case of low-density urban layouts. The orientation has a lower impact in the high-density cases (case 2, 3 and 6) as shown in fig. 9, and fig. 10. Moreover the results show that increasing obstruction heights can increase the energy use for heating because the solar radiation is blocked.

The Belgian situation was simulated with the same geometry and dynamic schedule as in the Vietnamese case. Again the results show that many parameters have an effect on the reduction of the energy consumption in buildings. Based on the optimal results fig. 11, building parameters are South-West window with 


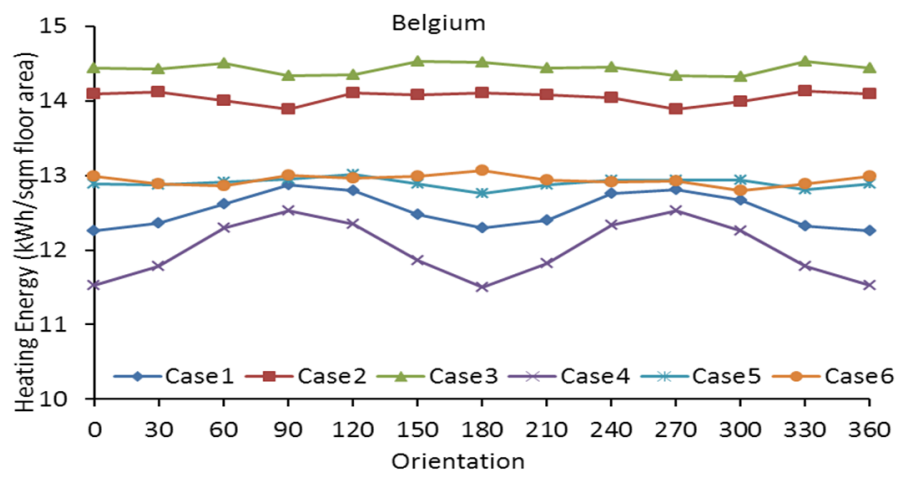

Figure 9: Heating energy of different orientations of six cases.

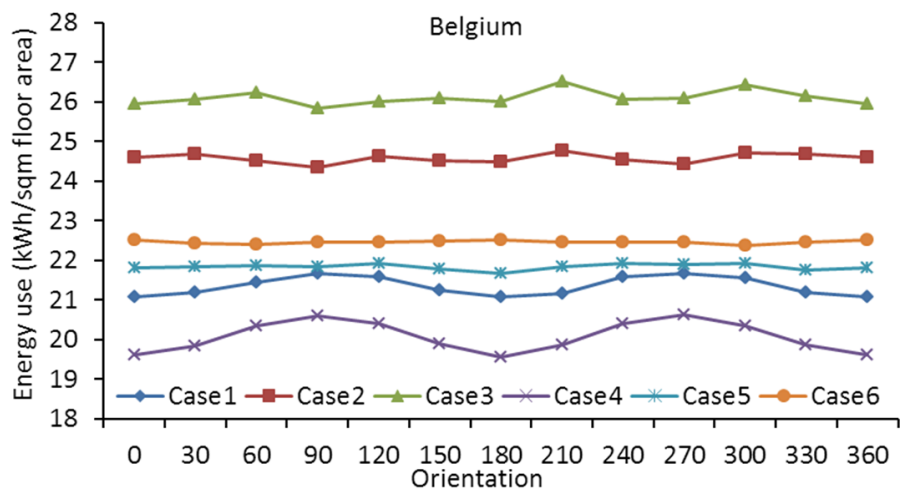

Figure 10: Energy use of six cases versus orientations, Belgium climate.

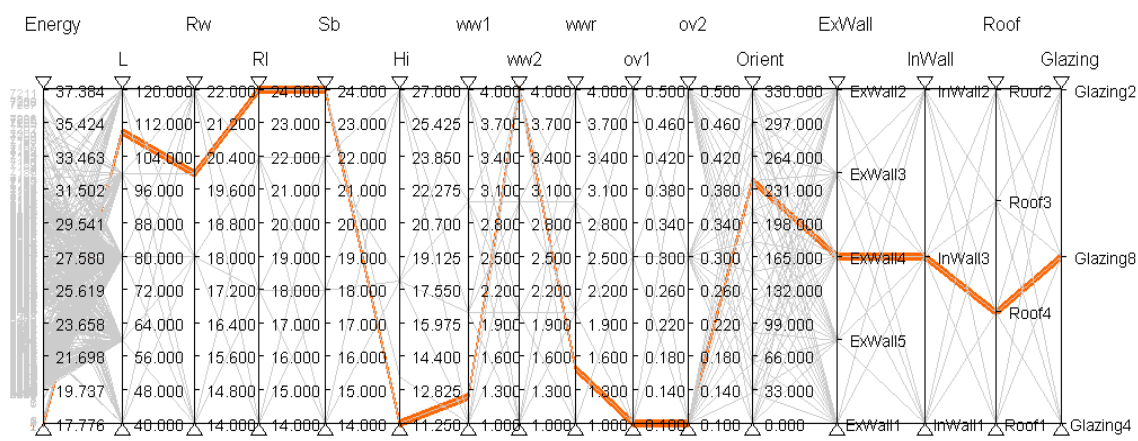

Figure 11: Parameters of optimal energy use are on yellow line based on design alternatives in Belgium climate. 
$33.8 \%$ façade, North-East window with $12.5 \%$ façade, windows with glazing composed of three layers Low emissivity Clear $4 \mathrm{~mm}$ glass filled with argon, without overhang, $20 \mathrm{~cm}$ clay brick external walls, and 1.5 by $1.5 \mathrm{~m}$ roof window. Urban parameters are $37.7 \%$ building density and South-West orientation. All parameters can be adapted with different orientations to increase solar gain via window and reduce heat loss from window surfaces. Hence, the model can work correctly in both tropical and temperate climate situations.

\section{Conclusions and recommendations}

In this paper a model is developed to analyse a simple building geometry in an urban layout. A dynamic schedule is created via the Energy Management System of EnergyPlus. The energy use of six urban layouts is analyzed, and GenOpt is used to optimize the energy use of different variants focussing on the material choice, building geometry and orientation.

Because of the large amount of design alternatives, the optimization process is able to support designers in the early designing stages to take decisions reducing the energy consumption, while guaranteeing thermal comfort. Another benefit of the parametric approach is the possibility to modify various parameters, including another climate context and other user life styles.

The aim of the test runs reported in this text was to validate the methodology in two different climatic contexts. A first conclusion is that the effect on ventilation and solar radiation of the urban layout can and should be considered on top of building parameters like: building geometry, building materials, occupant behaviours and thermal comfort.

A second conclusion is that for two or three parameters it might be possible to understand mutual effects, but in a large "design space $-8.7 * 10^{11}$ design options" as a result of many design parameters computer support by optimisation programs are required.

\section{References}

[1] Pekka Huovila, Mia Ala-Juusela, Buildings and climate change: Status, challenges and Opportunities, United Nations Environment Programme, Paris, France, 2007.

[2] Hirano, Y., Fujita, T., Evaluation of the impact of the urban heat island on residential and commercial energy consumption in Tokyo. Energy, 37, pp. 371-383, 2012.

[3] Strømann-Andersen, J., Sattrup, P.A., The urban canyon and building energy use: Urban density versus daylight and passive solar gains. Energy Build, 43, pp. 2011-2020, 2011.

[4] De Meester, T., Marique, A.-F., De Herde, A., Reiter, S., Impacts of occupant behaviours on residential heating consumption for detached houses in a temperate climate in the northern part of Europe. Energy Buil, 57, pp. 313-323, 2013. 
[5] Guerra Santin, O., Itard, L., Visscher, H., The effect of occupancy and building characteristics on energy use for space and water heating in Dutch residential stock. Energy Build, 41, pp. 1223-1232, 2009.

[6] Guerra Santin, O., Behavioural Patterns and User Profiles related to energy consumption for heating. Energy Build, 43, pp. 2662-2672, 2011.

[7] Nguyen, T.A., Aiello, M., Energy intelligent buildings based on user activity: A survey. Energy Build, 56, pp. 244-257, 2013.

[8] U.S. Department of Energy, EnergyPlus 8.1.0. EnergyPlus Energy Simul. Soft, 2014.

[9] Lawrence Berkeley National Laboratory, GenOpt. Generic Optim. Program, 2014.

[10] De Troyer, F., Element Method for Cost Control, BB/SfB-tabellen, Regie der gebouwen, Brussel, 1990.

[11] De Troyer, F., Graphical tools for cost-conscious design, 2003.

[12] Nguyen Van, T., De Troyer, F., Deriving Housing Preferences from advertising on the web for improving decision making by Economic and Social actors, in: Amsterdam University, Netherlands, 2013.

[13] Nicolas Heijmans, Peter Wouters, Impact of the uncertainties on wind pressures on the prediction of thermal comfort performances, 2003.

[14] B. Knoll, J.C. Phaff, W.F. de Gids, Pressure Simulation Program, in: Palm Springs, USA, 1995.

[15] Sun, Y., Heo, Y., Tan, M., Xie, H., et al., Uncertainty quantification of microclimate variables in building energy models. J. Build. Perform. Simul., 7, pp. 17-32, 2014.

[16] Fanger, P.O., Thermal comfort: analysis and applications in environmental engineering, Danish Technical Press Copenhagen, 1970.

[17] ISO 7730, ISO 7730, Ergonomics of the thermal environment - Analytical determination and interpretation of thermal comfort using calculation of the PMV and PPD indices and local thermal comfort criteria, 2005.

[18] ASHRAE, ASHRAE - Std 55-2004 Thermal Environmental Conditions for Human Occupancy, 2004.

[19] Fadzli Haniff, M., Selamat, H., Yusof, R., Buyamin, S., et al., Review of HVAC scheduling techniques for buildings towards energy-efficient and cost-effective operations. Renew. Sustain. Energy Rev, 27, pp. 94-103, 2013.

[20] Lin, Z., Deng, S., A study on the thermal comfort in sleeping environments in the subtropics-Measuring the total insulation values for the bedding systems commonly used in the subtropics. Building and Environment, 43, pp. 905-916, 2008. 